\title{
Mitral Valve Surgery for Rheumatic Lesions in Young Patients
}

World Journal for Pediatric and

Congenital Heart Surgery

2016, Vol. 7(3) 321-328

(C) The Author(s) 2016

Reprints and permission:

sagepub.com/journalsPermissions.nav DOI: I0.1।77/2I50।35।16637806 pch.sagepub.com

(SAGE

\author{
B. Cardoso, MD', P. Loureiro, MD', I. Gomes, MD', A. Gordo, MD', \\ N. Banazol, MD', I. Fragata, MD'3 , C. Trigo, MD', F. Pinto, MD', \\ and José Fragata, MD, PhD ${ }^{2}$
}

\begin{abstract}
Background: The appropriateness of rheumatic mitral valve repair remains controversial due to the risks of recurrent mitral dysfunction and need for reoperation. The aims of this study were to determine the overall short- and long-term outcomes of pediatric rheumatic mitral valve surgery in our center. Methods: Single-center, observational, retrospective study that analyzed the results of rheumatic mitral valve surgery in young patients, consecutively operated by the same team, between 1999 and 2014. Results: We included II 6 patients (mean age = $12.6 \pm 3.5$ years), of which 66 (57\%) were females. A total of II6 primary surgical interventions and 22 reoperations were performed. Primary valve repair was possible in 86 (74\%) patients and valve replacement occurred in 30 (26\%). Sixty percent of the patients were followed up beyond three months after surgery (median follow-up time $=9.2$ months [minimum $=10$ days; maximum $=15$ years]). Long-term clinical outcomes were favorable, with most patients in New York Heart Association functional class I (89.6\%) and in sinus rhythm (85\%). Freedom from reoperation for primary valve repair at six months, five years, and ten years was $96.4 \% \pm 0.25 \%, 72 \% \pm 0.72 \%$, and $44.7 \% \pm 1.34 \%$, respectively. Freedom from reoperation for primary valve replacement at six months, five years, and ten years was $100 \%, 91.7 \% \pm 0.86 \%$, and $91.7 \% \pm 0.86 \%$, respectively. Mitral stenosis as the primary lesion dictated early reintervention. Conclusions: Despite the greater rate of reoperation, especially when the primary lesion was mitral stenosis, rheumatic mitral valve repair provides similar clinical outcomes as compared with replacement, with the advantage of avoiding anticoagulation.
\end{abstract}

\section{Keywords}

mitral valve, rheumatic, pediatric, valve surgery

Submitted October 04, 2015; Accepted February 12, 2016

Presented at the 4th Meeting of the World Society for Pediatric and Congenital Heart Surgery, São Paulo, Brazil; July 20 I4.

\section{Introduction}

Rheumatic fever is caused by group A streptococcal infections, predominantly of the upper airway tract, secondarily inducing immunological reactions, that affect the heart, joints, and central nervous system. The heart valve lesions evolve over the years to scar the valves and produce severe hemodynamic changes, particularly in children and young adults. At least 15.6 million people are affected by rheumatic heart disease (RHD), and annually, over 230,000 will die from the disease around the globe. ${ }^{1}$ Rheumatic heart disease is the most common acquired heart disease in children in developing countries.

Rheumatic fever often presents with either acute or subacute valve lesions imposing treatment. The implantation of prosthetic heart valves in children is known to have major negative impacts on their immediate and long-term survival as well as on their quality of life and should, therefore, come only as an alternative resource. Valve repair is the primary goal, though it is recognized as technically challenging and more prone to failure, as the rheumatic process is truly evolutionary, making repair outcomes unstable. ${ }^{2,3}$

We present our single-center experience with the treatment of rheumatic mitral valve (MV) disease in young patients, mostly by valve repair, between 1999 and 2014. The aims of this study were to determine the overall short- and long-term outcomes of pediatric rheumatic MV surgery in our center and

\footnotetext{
' Department of Pediatric Cardiology, Hospital de Santa Marta, Centro Hospitalar de Lisboa Central, EPE, Lisbon, Portugal

${ }^{2}$ Department of Cardiothoracic Surgery, Hospital de Santa Marta, Centro Hospitalar de Lisboa Central, EPE, Lisbon, Portugal

${ }^{3}$ Department of Anesthesiology, Hospital de Santa Marta, Centro Hospitalar de Lisboa Central, EPE, Lisbon, Portugal
}

Corresponding Author:

José Fragata, Department of Cardiothoracic Surgery, Hospital de Santa Marta, Rua de Santa Marta, I 169-024 Lisboa, Portugal.

Email: jigfragata@gmail.com 


\begin{tabular}{|ll|}
\hline \multicolumn{2}{|l|}{ Abbreviations and Acronyms } \\
$\max$ & maximum \\
$\min$ & minimum \\
MR & mitral regurgitation \\
MS & mitral stenosis \\
MV & mitral valve \\
NYHA & New York Heart Association \\
PISA & proximal isovelocity surface area \\
RHD & rheumatic heart disease \\
TEE & transesophageal echocardiogram \\
\hline
\end{tabular}

compare the outcomes of repair versus replacement of the MV according to the predominant lesion.

\section{Patients and Methods}

\section{Study Design and Patient Selection}

A single-center, observational, retrospective study, based on data collection from the clinical files of consecutive patients with rheumatic MV disease, operated over a period of 15 years, by the same team comprising three independent surgeons.

This retrospective study was approved by the ethics committee of the hospital. All patients less than 25 years of age were eligible for the study. Patients undergoing concomitant surgery for aortic or tricuspid valves were not excluded.

\section{Clinical, Echocardiographic, and Laboratory Variables}

Preoperative variables included age, sex, type and severity of mitral disease at presentation, coexisting lesions, New York Heart Association (NYHA) functional class, rhythm status, and C-reactive protein serum level (in $\mathrm{mg} / \mathrm{L}$ ). C-reactive protein was considered elevated when $\geq 5 \mathrm{mg} / \mathrm{L}$.

On transthoracic echocardiography, the MV area was estimated using the pressure half-time method, and mitral stenosis (MS) was graded based on this and the mean pressure gradient across the valve. Severe MS was defined as an MV area $<1.0 \mathrm{~cm}^{2}$ and a mean pressure gradient across the valve $>10 \mathrm{~mm} \mathrm{Hg}^{4}$

With the simplified proximal isovelocity surface area (PISA) method, the degree of mitral regurgitation (MR) was graded as trivial or mild $(1+)$ : PISA radius $<3 \mathrm{~mm}$; moderate $(2+)$ : PISA radius 3 to $7 \mathrm{~mm}$; and severe $(3+)$ : PISA radius $\geq 7$ mm. ${ }^{5}$ Significant MR was defined as $>2+$.

Operative results included primary valve repair or primary valve replacement. Valve repair techniques included ring implantation, chordopexy, cord replacement, commissurotomy, and/or leaflet extension. Early mortality was defined as death within 30 days of surgery or in-hospital death.

Follow-up variables included follow-up time, reintervention status, severity of residual mitral disease, NYHA functional class, rhythm status, occurrence of embolic phenomena/major bleeding events, and late mortality. Late mortality was defined as death occurring after hospital discharge.
Early reoperation was defined as reoperation within the first six postoperative months. Midterm reoperation was defined as that occurring between the sixth postoperative month and five years. Late reoperation was defined as that occurring between the 5 th and the 15 th postoperative years.

\section{Surgical Technique}

Under general anesthesia and routine transesophageal echocardiogram (TEE), patients were operated by median sternotomy and cardiopulmonary bypass at $32^{\circ} \mathrm{C}$ mild hypothermia. Dual caval cannulation with aortic return, cross-clamp, and blood cardioplegia was standard. The MV was exposed through a standard incision behind the interatrial groove, after extensive $(2 \mathrm{~cm})$ mobilization of the right atrium to uncover the left atrial wall. No transseptal or biatrial incisions were made.

Carpentier's methodology was used, ${ }^{6}$ to sequentially assess the valve ring size and shape, its commissures, leaflets, and the subvalvar apparatus. Different techniques were usedextended commissurotomies, chordal mobilization, shortening or replacement of chordae, leaflet extension, and ring implantation-as appropriate. At the end of the procedure, surgical results were assessed by saline testing, intraoperative TEE analysis, and direct pressure measurements.

\section{Clinical Follow-Up}

Follow-up was conducted at the pediatric cardiology outpatient clinic, with clinical and echocardiographic evaluation. Patients were observed at regular six-month intervals. They were routinely kept under warfarin, for international normalized ratio levels of 2.5 to 3 , for a three-month period after repair, and indefinitely for prosthetic replacements and/or the coexistence of atrial fibrillation.

All patients were kept on secondary prophylaxis against the recurrence of acute rheumatic fever, with a monthly intramuscular injection of benzathine benzylpenicillin. ${ }^{7}$ Additionally, they were given antibiotic cover for endocarditis-prone procedures. $^{8}$

\section{Statistical Analysis}

Continuous variables were reported as means and standard deviation, if normally distributed, or as medians and range if not. Univariate analysis was performed using $\chi^{2}$ or Fisher exact test for categorical variables. Multifactorial analysis was performed using logistic regression analysis and Kaplan-Meier survival analysis. In both multifactorial tests, a dichotomized reintervention variable was used as the dependent variable and as the variable of interest.

In all analyses, a $P$ value $<.05$ was considered statistically significant. Statistical analysis was performed using SPSS software (v 20.0, IBM SPSS Software for Predictive Analytics; SPSS, Chicago, Illinois). 
Table I. Characteristics of the Young Patients Undergoing MV Surgery.

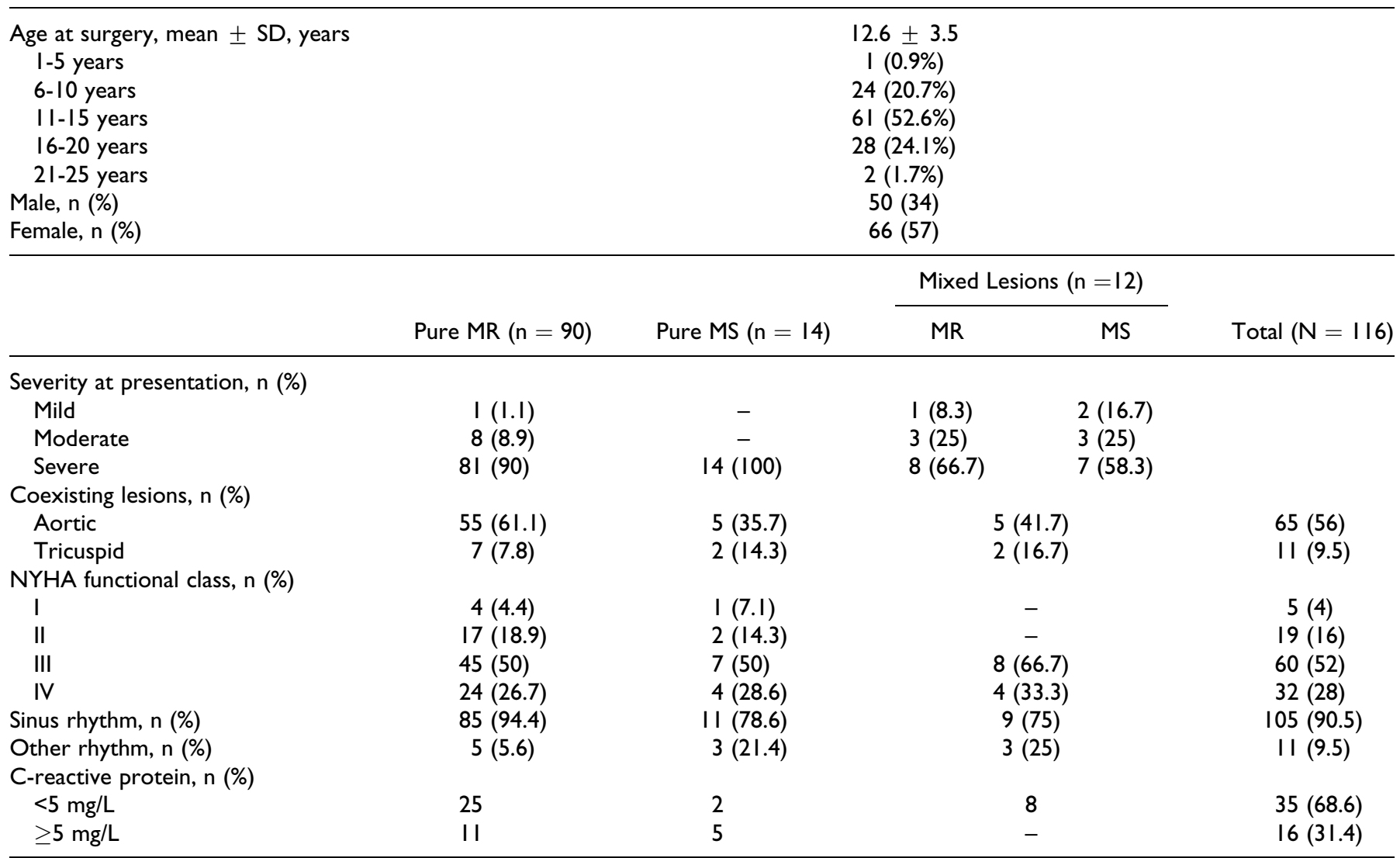

Abbreviations: MR, mitral valve regurgitation; MS, mitral valve stenosis; MV, mitral valve; NYHA, New York Heart Association.

\section{Results}

\section{Population Description}

We included 116 patients with a mean age of $12.6 \pm 3.5$ years, $66(57 \%)$ being females. A total of 138 surgical interventions were performed on these patients between 1999 and 2014 (Table 1).

Pure MR was present in $90(78 \%)$ patients, pure MS (12\%) in 14 patients, and combined MS and MR, mixed lesions, in 12 (10\%) patients. Coexisting conditions consisted of aortic involvement in $65(56 \%)$ patients, tricuspid involvement in $11(9.5 \%)$ patients, and atrial fibrillation in another $8(6.9 \%)$ patients.

At presentation, $60(52 \%)$ patients were in NYHA functional class III and $32(28 \%)$ patients in NYHA functional class IV. Of the 51 patients for whom preoperative acute-phase markers were available, C-reactive protein was found abnormally elevated in $16(31.4 \%)$ cases, suggesting the presence of rheumatic inflammation activity at the time of surgery. Although surgical intervention was normally postponed in the presence of acute disease, in some cases (16 patients), it was prompted by the severity of clinical manifestations and hemodynamic instability.

\section{Surgical Technique}

Mitral disease prompted surgical treatment in the majority of patients $(96.5 \%)$; in four cases, aortic valve disease
Table 2. Surgical Procedures Performed.

\begin{tabular}{|c|c|c|c|c|}
\hline & $\begin{array}{l}\text { Pure MR } \\
(n=90)\end{array}$ & $\begin{array}{l}\text { Pure MS } \\
(n=14)\end{array}$ & $\begin{array}{l}\text { Mixed } \\
\text { Lesions } \\
(n=12)\end{array}$ & Overal \\
\hline Primary valve repair, n (\%) & $73(81.1)$ & $8(57.1)$ & $5(4 I .7)$ & $86(74)$ \\
\hline Carpentier ring, $\mathrm{n}$ & 63 & I & 4 & 68 \\
\hline $\begin{array}{l}\text { Chordopexy/cord } \\
\text { replacement, } n\end{array}$ & 52 & 2 & - & 54 \\
\hline Commissurotomy, $\mathrm{n}$ & 69 & 7 & 3 & 79 \\
\hline Leaflet extension, $\mathrm{n}$ & 48 & - & - & 48 \\
\hline $\begin{array}{l}\text { Primary valve replacement, } \\
\mathrm{n}(\%)\end{array}$ & $17(18.9)$ & $6(42.9)$ & $7(58.3)$ & $30(26)$ \\
\hline
\end{tabular}

Abbreviations: MR, mitral valve regurgitation; MS, mitral valve stenosis.

predominated, the MV being approached in the context of aortic valve surgery (Tables 1 and 2).

Primary valve repair was possible in $86(74 \%)$ patients. In $68(79 \%)$ of the MV repair patients, a semirigid Carpentier's prosthetic ring was applied (sizes \# 26-34) as part of the repair, complementing other standardized techniques. Chordopexy or cord replacement was common, having been applied to 54 $(63 \%)$ of the patients.

Valve replacement was the primary surgical option in 30 (26\%) patients. In this group, prosthetic valves sizes \#18 to 29 were implanted. 
Table 3. Follow-Up Characteristics of the Young Patients After MV Surgery.

$\begin{array}{lc}\text { NYHA functional class, } \mathrm{n}(\%) & \\ \text { II } & 104(89.6) \\ \text { Missing information } & 7(6) \\ \text { Sinus rhythm, } \mathrm{n}(\%) & 5(4.4) \\ \text { Embolic phenomena, } \mathrm{n}(\%) & 99(85) \\ \text { Residual mitral stenosis, } \mathrm{n}(\%) & 5(4.3) \\ \quad \text { Mild } & \\ \text { Moderate } & 18(78.3) \\ \text { Severe } & 5(21.7) \\ \text { Total } & - \\ \text { Residual mitral regurgitation, } \mathrm{n}(\%) & 23(100) \\ \quad \text { Mild } & \\ \text { Moderate } & 41(70.6) \\ \text { Severe } & 16(27.5) \\ \text { Total } & 1(1.9) \\ \end{array}$

Abbreviations: MV, mitral valve; NYHA, New York Heart Association.

\section{Early Surgical Outcomes}

No operative mortality was registered. Overall, 20 (17\%) patients experienced early surgical complications: rhythm disturbances $(n=9)$, ventricular dysfunction $(n=5)$, hemodynamically significant pericardial effusion $(\mathrm{n}=3)$, pneumothorax $(\mathrm{n}=2)$, and catheter-associated septicemia $(\mathrm{n}=1)$. There was no significant association between the type of surgery performed and the occurrence of early complications $(P=.89)$.

\section{Late Outcomes}

Sixty percent of the patients were followed up beyond three months after surgery. Median follow-up time was 9.2 months (minimum $[\mathrm{min}]=10$ days; $\operatorname{maximum}[\max ]=15$ years; Table 3).

The wide range in follow-up times is due to the high proportion of African patients who returned to their countries of origin as soon as their clinical status allowed for transfer. In our analysis, once these patients return to their countries of origin, they are considered lost to follow-up and censored.

At the time of the latest outpatient clinic visit, most $(89.6 \%)$ of the patients were in NYHA functional class I, the vast majority (93\%) showing clinical improvement from presentation. There were no patients in functional class III or IV.

Of the $58(50 \%)$ patients with residual MR, only one had severe $(>2+)$ regurgitation. Twenty-three $(20 \%)$ patients presented with residual MS, all with mild to moderate disease.

Most $(85 \%)$ of the patients had normal sinus rhythm. Five (4.3\%) patients experienced thromboembolic phenomena: three prosthetic valve thrombosis and two nonlethal cerebral thromboembolisms. Both patients with cerebral thromboembolism had atrial fibrillation. There were no documented major bleeding events or late mortality.
Table 4. Reintervention Rate per Characteristics.

\begin{tabular}{lccc}
\hline & Reintervention, $\mathrm{n}$ & OR $(95 \% \mathrm{Cl})$ & $P$ \\
\hline $\begin{array}{l}\text { Preoperative elevated } \\
\text { C-reactive protein }\end{array}$ & 4 & & .240 \\
$\begin{array}{l}\text { Type of primary surgery } \\
\text { Valve repair }\end{array}$ & 19 & $8.22(1.05-64.4)$ & .023 \\
$\quad$ Valve replacement & 3 & & \\
$\begin{array}{l}\text { Surgeon of primary } \\
\text { procedure }\end{array}$ & & & \\
$(1)^{\mathrm{a}}$ & 12 & $0.59(0.22-1.60)^{\mathrm{b}}$ & .293 \\
$(2)^{\mathrm{a}}$ & 5 & $1.44(0.47-4.49)^{\mathrm{b}}$ & .543 \\
$(3)^{\mathrm{a}}$ & 3 & $1.71(0.42-6.96)^{\mathrm{b}}$ & .432 \\
\hline
\end{tabular}

Abbreviations: $\mathrm{Cl}$, confidence interval; OR, odds ratio.

${ }^{a}$ Each number represents a different surgeon.

${ }^{b}$ The reference category is the combined results of the other two surgeons.

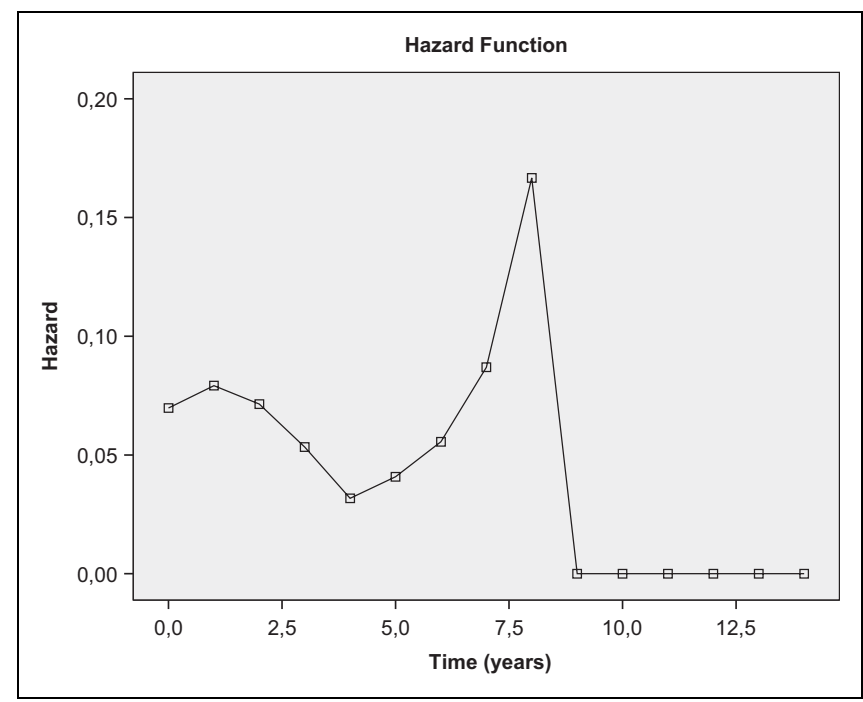

Figure I. Hazard function for reintervention (time in years).

\section{Reintervention}

Twenty (17\%) patients were submitted to a total of 22 reoperations, in a median 22.7 months after primary surgery (min: 14 days; max: 8.5 years). The primary valve surgery was valve repair in 19 of the patients and valve replacement in 3 (Table 4). Reoperations were predominantly performed for MV dysfunction.

During reoperation, MV replacement was performed in 20 (91\%) patients and a second MV repair done in $2(9 \%)$. Interestingly, reoperation was found to have a bimodal peak: initially around 16 weeks postoperatively and midterm (Figure 1). There were 6 (27.4\%) early, 13 (59\%) midterm, and 3 (13.6\%) late reoperations.

A log-rank test was run to determine whether there were differences in the time elapsed until reintervention for the three types of MV disease: MR, MS, and mixed lesions. Reintervention was significantly earlier for MS (median time to reintervention $=42$ months) as compared to MR (median time to reintervention $=107$ months), $P=.012$. There were no statistically significant differences between the two types 


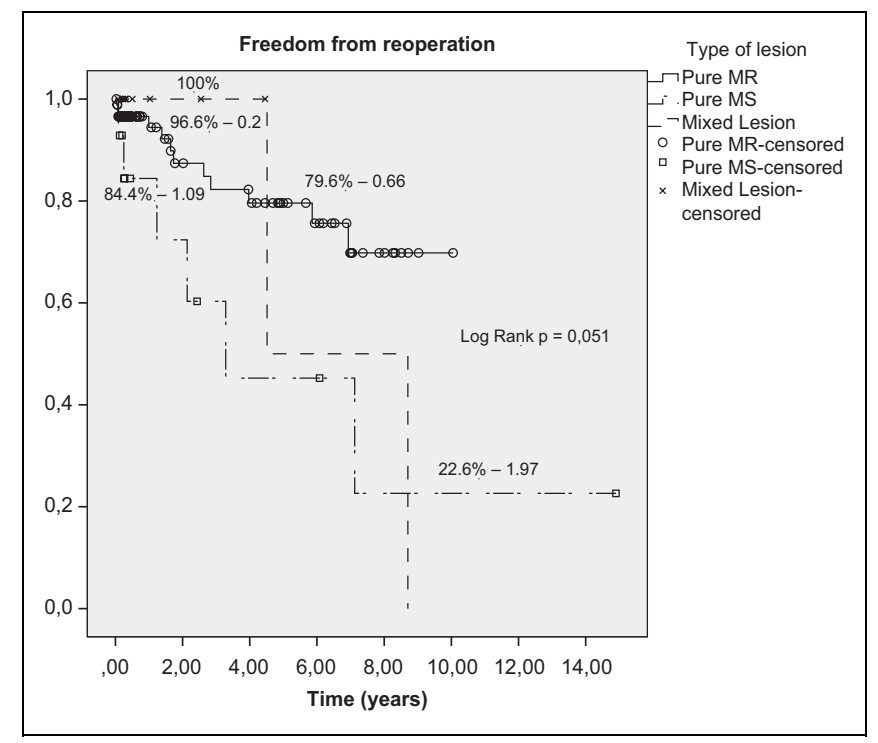

Figure 2. Kaplan-Meier survival function for reintervention by type of lesion (time in years).

of lesions mentioned above and the mixed lesions (median time to reintervention $=98$ months), $P=.05$ (Figure 2).

For MR, freedom from reoperation at six months and five years was $96.6 \% \pm 0.20 \%$ and $84.4 \% \pm 1.09 \%$, respectively. For MS, freedom from reoperation at six months and five years was $79.6 \% \pm 0.66 \%$ and $22.6 \% \pm 1.97 \%$, respectively. Freedom from reoperation by grade of residual mitral stenosis and regurgitation is shown in Figures 4 and 5, respectively.

The only significant association to predict reintervention was the type of the primary surgical option, with primary valve repair having an odds ratio of 8.22 (95\% confidence interval: 1.05-64.4) for reintervention when compared to primary valve replacement $(P=.023)$.

Both the preoperative elevated C-reactive protein and the surgeon performing the primary procedure showed no significant association with the rate of reintervention, even when adjusted for the type of primary procedure in the multivariate analysis (Table 4).

Median time to reintervention after primary valve replacement was 90 months, whereas median time to reintervention after primary valve repair was 108 months (Figure 3).

Freedom from reoperation for primary valve repair at six months, five years, and ten years was $96.4 \% \pm 0.25 \%, 72 \% \pm$ $0.72 \%$, and $44.7 \% \pm 1.34 \%$, respectively. Freedom from reoperation for primary valve replacement at six months, five years, and ten years was $100 \%, 91.7 \% \pm 0.86 \%$, and $91.7 \% \pm 0.86 \%$, respectively.

\section{Comment}

Valve lesions due to RHD are common, mostly in patients coming from developing countries, and its prevalence is gaining more relevance with recent migrations. The treatment for these patients represents both a medical and surgical challenge and also a burden. Being an old lesion, recent papers in the

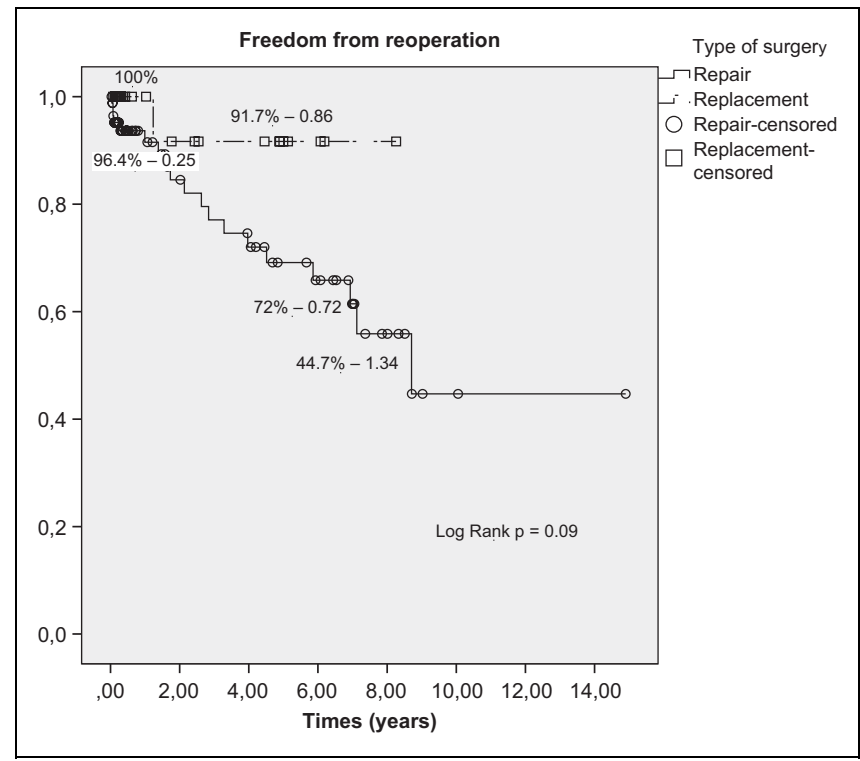

Figure 3. Kaplan-Meier survival function for reintervention by type of surgery (time in years).

literature ${ }^{2,3}$ are bringing this subject to present attention, meaning that this is an unresolved issue for medicine.

In this article, we described our results for a young RHD patient population consecutively treated over 15 years, with a primary intention to repair their MVs. We described in the series what concerns patients' preoperative differential characteristics, surgical repair techniques used, and achieved outcomes, both early and late.

Transformation of the acute inflammatory process into fibrosis, over time, is the main pathological mechanism responsible for impairing valve function, MV being the one most frequently affected in rheumatic carditis. Valvular fibrosis can be exacerbated by recurrent rheumatic fever episodes and can affect both the valvar leaflets and the subvalvular apparatus by increasing tissue thickness, gradual scaring, and retraction, leading to deformation and subsequent calcification over time.

In acutely presenting patients, the primary lesion is normally annular dilatation (Carpentier type I lesion) ${ }^{6}$ and frequently anterior leaflet prolapse, due to inflammatory chord elongation (Carpentier type IIa lesion). ${ }^{6}$ Some of these patients will additionally have myocardial ventricular dysfunction due to inflammatory pancarditis.

In patients presenting with already established lesions, MR was present in $90(77.6 \%)$, MS in $14(12.1 \%)$, and mixed lesions in another $12(13.4 \%)$ patients.

We will discuss the techniques used to treat each anatomical form and their impacts on long-term outcomes. Typically, established lesions causing MR consist of coexisting Carpentier type II (involving A2 segment) and type IIIa (involving the posterior leaflet, invariably retracted by scaring), whereas lesions causing MS consist of commissural fusion, not rarely extending to chordae and papillary muscles, all involved in the fibrotic process, representing Carpentier type III lesions. ${ }^{6}$ Invariably, the mitral annulus will lose its oval shape to become 
Table 5. Main Features of Other Studies on RHD Mitral Valve Repair in Children. ${ }^{18,19,20,21}$

\begin{tabular}{|c|c|c|c|c|c|c|}
\hline Study & Population & Age & Operative Techniques & $\begin{array}{l}\text { Early } \\
\text { Mortality }\end{array}$ & $\begin{array}{l}\text { Late } \\
\text { Mortality }\end{array}$ & $\begin{array}{l}\text { Reoperation } \\
\text { Rate }\end{array}$ \\
\hline I & $\begin{array}{l}\mathrm{n}=22(19 \mathrm{MV} \\
\text { repair/3 MV } \\
\text { replacement })\end{array}$ & $14.3 \pm 3.8$ years & $\begin{array}{l}\text { Rumel debridement; prosthetic ring annuloplasty; partial } \\
\text { posterior annuloplasty; commissurotomy; commissuroplasty }\end{array}$ & $0 \%$ & $2(7.7 \%)$ & $5(23 \%)$ \\
\hline 2 & $\mathrm{n}=278$ & $11.7 \pm 2.9$ years & $\begin{array}{l}\text { Posterior collar annuloplasty; commissurotomy, cusp-level } \\
\text { chordal shortening, cusp thinning, cleft suture, and cusp } \\
\text { excision or plication }\end{array}$ & $6(2.2 \%)$ & $7(2.6 \%)$ & $16(6 \%)$ \\
\hline 4 & $\mathrm{n}=36$ & $11.3 \pm 3.9$ years & Leaflet suspension to the contralateral annulus & $0 \%$ & $0 \%$ & $3(8.3 \%)$ \\
\hline
\end{tabular}

Abbreviations: MV, mitral valve; RHD, rheumatic heart disease.

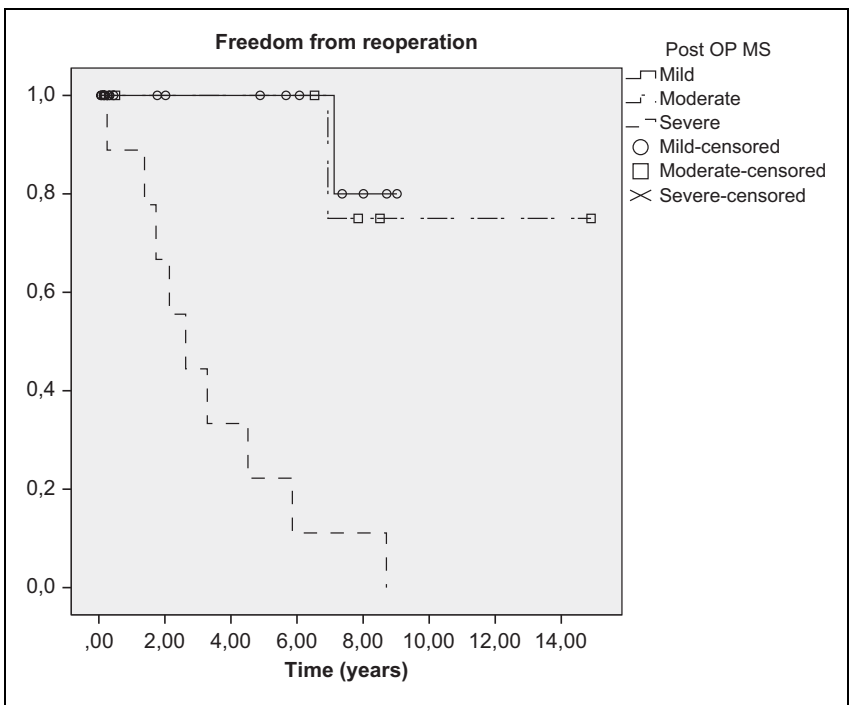

Figure 4. Kaplan-Meier survival function for reintervention by grade of residual mitral stenosis (time in years).

circular, and this type I lesion impairs leaflet coaptation and worsens MV regurgitation.

In our series, individualized surgical techniques were used to address every lesion oriented by TEE at the time of surgery.

Annulus dilatation and deformity were always treated by prosthetic ring implantation, in order to correct the native mitral annulus remodeling and to improve long-term durability of the repair. The major disadvantage of ring implantation is that sizes below 26 are potentially restrictive in a growing child and more so in the face of MS as the presenting dominant lesion.

Nevertheless, ring implantation seems mandatory, as failure to perform annuloplasty at the time of the initial valve repair has been reported as a predictive factor of early reoperation ${ }^{9,10}$; this is also confirmed by our earlier personal experience. Some authors claim that the implantation of pediatric biodegradable rings will achieve superior results, not only at the valve level

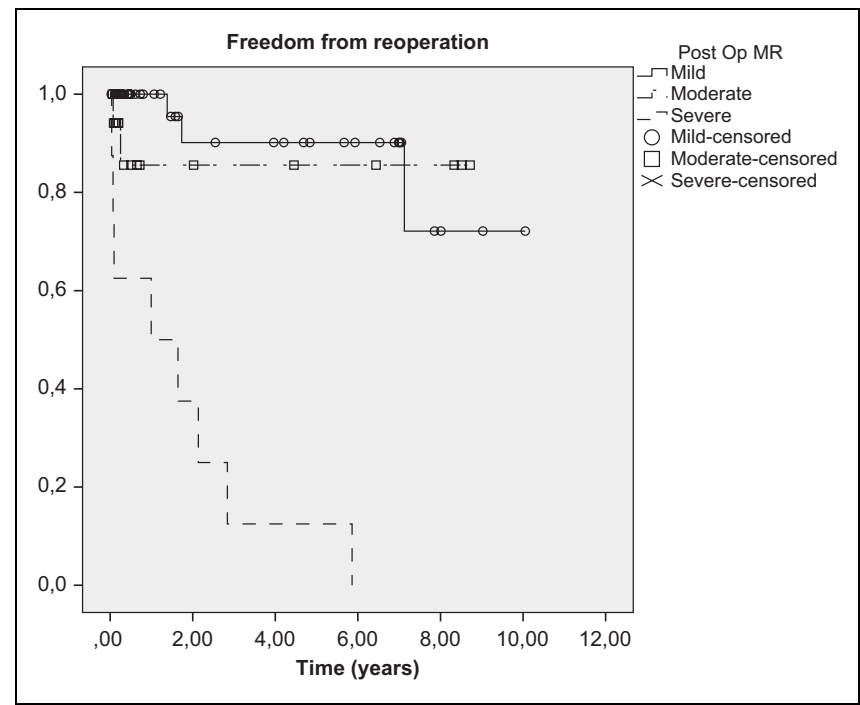

Figure 5. Kaplan-Meier survival function for reintervention by grade of residual mitral regurgitation (time in years).

but also by better preserving ventricular geometry and function $^{11}$ (Table 5).

Over the years, we have opted to compromise with the implantation of semirigid rings (as flexible rings do not seem to allow for stable repairs in patients with RHD) and by using as large as possible rings, its size guided mainly by the intertrigone distance and the area of the anterior leaflet (although these measurements might be affected by the rheumatic scaring process itself).

In a previous study from our group, ${ }^{12}$ we have demonstrated that the correlation between patient body surface area and MV ring size is by no means perfect in this growing rheumatic population. In fact, we were able to demonstrate that whenever pericardial extension was used to correct posterior leaflet retraction, a bigger size ring could be implanted, reducing the likelihood of early restenosis. Ring size did correlate significantly with the use of posterior leaflet extension. 
Also, extending the posterior leaflet, ideally with autologous prefixed pericardium, as well as sectioning secondary chordae, commonly fused, improves leaflet coaptation. In this cohort, posterior leaflet extension and secondary chord sectioning were done in $67 \%$ of the cases (please note that MR was present in $77.6 \%$ of the population, therefore, pericardial extension was indeed a common procedure).

On the anterior leaflet, extension is almost never needed, but all efforts must concentrate on correcting any existing leaflet prolapse due to chordal elongation, and this is usual for the A2 segment.

Prolapse of the anterior leaflet, caused by chord elongation or, more rarely, rupture, commonly affecting A2 segment can be corrected by chord shortening, chord transfer, or artificial chord implantation. Chord shortening and transfer techniques were chosen according to the degree of thickness and retraction of primary anterior chordae tendineae ( $63 \%$ in this cohort). In the active carditis, we tried, whenever possible, to avoid both chord shortening and transfer techniques because of the tissue fragility induced by the inflammatory process. In such cases, the use of artificial chords reinforced with small pericardial pledgets at both implantation sites can potentially decrease the rate of early repair failure. ${ }^{13}$

Restricted motion of the anterior and/or posterior leaflets due to commissural fusion can be treated by commissurotomy ( $92 \%$ in this cohort), usually extending to, and splitting the papillary muscles and also by resection/mobilization of the secondary posterior chordae, by direct leaflet thinning, and by leaflet enlargement using autologous pericardium.

In $30(26 \%)$ patients, the extension of the scaring process and/or the presence of calcifications dictated primary valve replacement by a mechanical prosthesis, the native valve being deemed as not repairable.

We had a low percentage of short-term complications $(17 \%)$ that favorably compare to those described in the literature. ${ }^{10,14-16}$ Furthermore, no early surgical mortality was documented.

Clinical long-term outcomes until 15 years of follow-up were also favorable, with most $(89.6 \%)$ patients in NYHA functional class I and the majority $(85 \%)$ in sinus rhythm. At the time of the latest evaluation, $81(69.8 \%)$ patients presented with some kind of residual lesion, $73 \%$ being classified as mild and only $1.2 \%$ as severe. Five (4.3\%) patients experienced thromboembolic phenomena. Notably, three of these patients had a prosthetic valve thrombosis related to anticoagulation therapy noncompliance.

Interestingly, reoperation, whenever needed, was found to have a bimodal peak distribution, initially around 16 weeks postoperatively and midterm (six months to five years postoperatively).

The early peak in the instantaneous hazard might be attributed to suboptimal repair or inherent extreme complexity of the disease process. Residual MR $>1+$ and lack of concomitant ring annuloplasty have been identified in the literature as predictors of repair failure. ${ }^{10,13,17}$ Moreover, Yakub and colleagues demonstrated that rheumatic MV repair at a younger age $(<20$ years) was an independent predictor of reoperation and valve failure. ${ }^{2}$
In this cohort, MS as the primary lesion has dictated the need for early reintervention, with a median time to reintervention of 42 months, as compared to MR, with a median time to reintervention of 107 months, $P=.012$. Mitral stenosis is widely recognized as a risk factor for reoperation.

It has been recognized that acute inflammation does predict a poorer outcome. ${ }^{13}$ In the study population, however, elevated preoperative C-reactive protein levels did not correlate with the reoperation rate, probably due to the small number of patients in these conditions (16 patients). However, it seems wise to stabilize patients preoperatively with anti-inflammatory agents and to defer surgery until their rheumatic activity lowers.

In our population, midterm failures have been attributed to recurrence and/or progression of the inflammatory rheumatic process. It is our belief that continuing disease process and/or recurrent disease is the main cause of late valve failure at younger ages. That is why we have kept all our patients postoperatively on penicillin prophylaxis.

In our series, freedom from reoperation for primary valve repair at six months, five years, and ten years was $96.4 \% \pm$ $0.25 \%, 72 \% \pm 0.72 \%$, and $44.7 \% \pm 1.34 \%$, respectively. Freedom from reoperation for primary valve replacement at six months, five years, and ten years was $100 \%, 91.7 \% \pm$ 0.86 , and $91.7 \% \pm 0.86$, respectively.

Although a higher reoperation rate for MV repair was expected and extensively described in the literature, the difference in freedom from reoperation for the two procedures - valve repair or replacement - lies in the great disparity of patients submitted to primary repair (74\%) versus replacement (26\%).

Indeed, in a review of a 40 -year experience with pediatric MV replacement in an heterogeneous group of 97 patients with congenital and acquired mitral disease, Brown and colleagues found high rates $(35 \%)$ of reoperation (freedom from reoperation at 10 years $=71 \%$ and at 20 years $=63 \%$ ). Also, very high levels of valve-related complications and late mortality have occurred in their series. They concluded that MV replacement should be reserved only for medical and repair failures. ${ }^{15}$

In conclusion, despite the greater rate of reoperation, rheumatic MV repair provides noninferior clinical outcomes, as compared to MV replacement. However, it has the advantage of being associated with fewer thromboembolic events, particularly in a pediatric population, fairly noncompliant to anticoagulation, and more so in developing countries, where access to hypocoagulation control is limited. In addition to this, somatic growth and pregnancy remain important issues in young patients. ${ }^{2}$

Therefore, although patients with RHD present special challenges, MV repair should be preferred over prosthetic replacement, whenever technically possible. In our center, the overall short- and long-term outcomes of pediatric rheumatic MV repair are good and compare most favorably with those described in the literature.

\section{Study limitations}

This study is based on a single-center series that is susceptible to referral bias and institution-specific practices. The 
nonrandomized design may have affected the results due to the presence of unmeasured confounders, procedure bias, or detection bias, despite the use of statistical adjustments. The variations in results depend on the attending surgeon's discretion regarding different techniques and the level of acceptance of their repair results.

\section{Acknowledgments}

The authors wish to thank Dr Tiago Costa for his help in the statistical analysis of data.

\section{Declaration of Conflicting Interests}

The author(s) declared no potential conflicts of interest with respect to the research, authorship, and/or publication of this article.

\section{Funding}

The author(s) received no financial support for the research, authorship, and/or publication of this article.

\section{References}

1. Mendis S, Pekka P, Norrving B. Global atlas on cardiovascular disease prevention and control. Geneva, Switzerland: World Health Organization; 2011.

2. Yakub MA, Dillon J, Krishna Moorthy PS, Pau KK, Nordin MN. Is rheumatic aetiology a predictor of poor outcome in the current era of mitral valve repair? Contemporary long-term results of mitral valve repair in rheumatic heart disease. Eur J Cardiothorac Surg. 2013;44(4): 673-681.

3. Dillon J, Yakub MA, Kong PK, Ramli MF, Jaffar N, Gaffar IF. Comparative long-term results of mitral valve repair in adults with chronic rheumatic disease and degenerative disease: Is repair for "burnt-out" rheumatic disease still inferior to repair for degenerative disease in the current era? $J$ Thorac Cardiovasc Surg. 2015;149(3): 771-779.

4. Baumgartner H, Hung J, Bermejo J, et al. Echocardiographic assessment of valve stenosis: EAE/ASE recommendations for clinical practice. Eur J Echocardiogr. 2009;10(1): 1-25.

5. Lancellotti P, Moura L, Pierard LA, et al. European Association of Echocardiography recommendations for the assessment of valvular regurgitation. Part 2: mitral and tricuspid regurgitation (native valve disease). Eur J Echocardiogr. 2010;11(4): 307-332.

6. Carpentier A. Cardiac valve surgery-the "French correction". J Thorac Cardiovasc Surg. 1983;86(3): 323.

7. Gerber MA, Baltimore RS, Eaton CB, et al. Prevention of rheumatic fever and diagnosis and treatment of acute Streptococcal pharyngitis: a scientific statement from the American Heart Association Rheumatic Fever, Endocarditis, and Kawasaki Disease Committee of the Council on Cardiovascular Disease. Circulation. 2009;119(11): 1541-1551.
8. White H, Walsh W, Brown A, et al. Rheumatic heart disease in indigenous populations. Heart Lung Circ. 2010;19(5): 273-281.

9. Yau TM, El-Ghoneimi YA, Armstrong S, Ivanov J, David TE. Mitral valve repair and replacement for rheumatic disease. J Thorac Cardiovasc Surg. 2000;119(1): 53-61.

10. Bernal JM, Pontón A, Diaz B, et al. Combined mitral and tricuspid valve repair in rheumatic valve disease: fewer reoperations with prosthetic ring annuloplasty. Circulation. 2010;121(17): 1934-1940.

11. Kalangos A, Sierra J, Vala D, et al. Annuloplasty for valve repair with a new biodegradable ring: an experimental study. $J$ Heart Valve Dis. 2006;15(6): 783.

12. Fragata J, Coelho P, Banazol N, Nogueira G, Trigo C. Cirurgia de Reparação Mitral em Crianças com Valvulopatia Adquirida. Revista Portuguesa de Cirurgia Cardiotorácica e Vascular. 2004;IX(4): 189-193.

13. Kalangos A. The rheumatic mitral valve and repair techniques in children. Semin Thorac Cardiovasc Surg Pediatr Card Surg Annu. 2012;15(1): 80-87.

14. Kojori F, Chen R, Caldarone CA, et al. Outcomes of mitral valve replacement in children: a competing-risks analysis. $J$ Thorac Cardiovasc Surg. 2004;128(5): 703-709.

15. Brown JW, Fiore AC, Ruzmetov M, Eltayeb O, Rodefeld MD, Turrentine MW. Evolution of mitral valve replacement in children: a 40-year experience. Ann Thorac Surg. 2012;93(2): 626-633; discussion 633.

16. Edwin F, Aniteye E, Tettey MM, Tamatey M, Frimpong-Boateng $\mathrm{K}$. Outcome of left heart mechanical valve replacement in West African children - a 15-year retrospective study. J Cardiothorac Surg. 2011;6(1): 57.

17. Schaff HV. Mitral valve repair in patients with rheumatic heart disease: what are the limits? J Thorac Cardiovasc Surg. 2015; 149(3): 779-780.

18. Hillman ND, Tani LY, Veasy LG, et al. Current status of surgery for rheumatic carditis in children. Ann Thorac Surg. 2004;78(4): 1403-1408.

19. Talwar S, Rajesh MR, Subramanian A, Saxena A, Kumar AS. Mitral valve repair in children with rheumatic heart disease. $J$ Thorac Cardiovasc Surg. 2005;129(4): 875-879.

20. Kalangos A, Christenson JT, Beghetti M, et al. Mitral valve repair for rheumatic valve disease in children: midterm results and impact of the use of a biodegradable mitral ring. Ann Thorac Surg. 2008;86(1): 161-169.

21. Myers P, Christenson J, Cikirikcioglu M, et al. Leaflet suspension to the contralateral annulus to address restriction or tetheringinduced mitral and tricuspid regurgitation in children. Results of a case-control study. J Thorac Cardiovasc Surg. 2010;140: 1110-1116. 